\title{
Analysis of China's Core Literacy Research Based on Keyword Clustering
}

\author{
Yuan Qiu1, Xiaotao Lu' , Taisheng Fu², Deli $\mathrm{Du}^{3}$ \\ ${ }^{1}$ College of Education Science, Gannan Normal University, Ganzhou, China \\ ${ }^{2}$ Jiangxi University Humanities and Social Science Key Research Base Gannan Normal University Educational Economic Research \\ Center, Ganzhou, China \\ ${ }^{3}$ College of Education Science, Jiaying College, Meizhou, China
}

Email: 13824577584@163.com

How to cite this paper: Qiu, Y., Lu, X. T., Fu, T. S., \& Du, D. L. (2019). Analysis of China's Core Literacy Research Based on Keyword Clustering. Creative Education, 10, 1002-1022.

https://doi.org/10.4236/ce.2019.105076

Received: April 30, 2019

Accepted: May 27, 2019

Published: May 30, 2019

Copyright $\odot 2019$ by author(s) and Scientific Research Publishing Inc. This work is licensed under the Creative Commons Attribution International License (CC BY 4.0).

http://creativecommons.org/licenses/by/4.0/

(c) (i) Open Access

\begin{abstract}
At present, core literacy has become a hot topic in the field of education research in China. By combing the relevant achievements of China's core literacy research, researchers can have a further insight into the research status of this field, which has important implications for the future development of China's core literacy research, in this study, taking the 376 core literacy-related periodical papers of "Core Journals" and "CSSCI" in CNKI as the research object. BICOMB and SPSS software are used to knowledge map visualization and analyze the published date, published author unit, journal publication amount, high-frequency keyword confirmation, high-frequency keyword matrix analysis, and others of literature data. The results show China's current core literacy research mainly around on the following four areas. One is research on strengthening morality education and student's developing core literacy and its personnel training. Two is basic education curriculum teaching reform based on core literacy and its practical research. Three is research on discipline core accomplishment and classroom teaching and its cultivation path. Four is research on school-based curriculum and its development under the perspective of core accomplishment. Finally, on the basis of summarizing the conclusions of this study, the author puts forward the deficiencies of the research and suggestions for future core literacy research.
\end{abstract}

\section{Keywords}

Core Literacy, Keywords Clustering, Knowledge Map, Visualization Analysis

\section{Introduction}

The 21st century is an era of great changes. The tide of economic globalization, 
scientific and technological informatization, and knowledge explosion are surging up. Various fields at different stages of development are brought into the same framework for collision and interaction. This change also poses an unprecedented challenge for the education field of countries of the world, and it is in response to this challenge that core literacy has emerged. Throughout the changes in core literacy research, in the international community, core literacy has not yet formed a unified conclusion, but there have been many academic achievements and practical explorations. In China, the core literacy did not cause many repercussions when it was first proposed. Instead, it quickly attracted widespread attention after 2013, and set off a "Core Literacy Heat" in 2016 which became a "hot word" in the education field of China. At the same time, China's academic circles have conducted multidimensional research on core literacy, and the research results have shown an explosive growth trend. Therefore, reviewing and combing the research results of China's core literacy in a timely manner will help to provide reference for China's core literacy research in the future, and also introduce the status quo of China's core literacy research to countries around the world, in order to let the countries of the world understand the situation of China's basic education reform and development. This paper is divided into six chapters. The first chapter is the introduction. The second chapter is literature review. The third chapter is the data source. The fourth chapter is the research method. The fifth chapter is data processing and result analysis. The sixth chapter, based on the analysis of the above results, from the main body, content, perspective, methods and shortcomings of the study, makes a general summary, and on this basis, puts forward suggestions for future research on China's core literacy.

\section{Literature Review}

The concept of "core literacy" originates from European Union (EU) countries. From March 23 to 24, 2000, at the special summit held in Lisbon, Portugal, leaders of the $15 \mathrm{EU}$ countries reached a consensus on the EU's economic development plan for the next decade, forming the "Lisbon Strategy". And the "Education-training 2010 Plan (ET2010)" with "Lifelong Learning Plan" is the response of the education field to Lisbon Strategy. It is in this style of Time background that the core literacy of the EU has gradually come into being. There are three initial sources of EU core literacy: The first is the traditional "read, write, calculate" basic ability. The second is the "new basic ability" proposed by the "Lisbon Strategy" in 2000, which mainly includes IT skills, foreign language ability, technical culture, entrepreneurship and social skills (European Council, 2000). The third is the expansion of "Working Group B", which is responsible for core literacy research, on the basis of the first two. And in March 2002, the first version of eight core literacy was proposed, including: IT skills, foreign language ability, and technical culture, entrepreneurship, social skills, interpersonal relationships and civic literacy, learning to learn and cultural common sense (Docin, 2015). Since then, based on extensive research and a large number 
of expert consultations, an official version of core literacy was released in 2006. It mainly includes: Communication in mother tongue, communication in foreign language, mathematical literacy and basic scientific literacy, digital literacy, learning to learn, social and civic literacy, active consciousness and entrepreneurial spirit, cultural awareness and expression (European Union, 2006).

With the wave of education reform in EU countries, China also has launched a new round of basic education curriculum teaching reform in the 21st century. In June 2001, the ministry of education of the People's Republic of China issued the "Outline of Curriculum Reform for Basic Education (Trial)", which clearly set out the specific objectives of curriculum reform for basic education. In May 2013, professor Lin, C. D. from Beijing Normal University of China undertook the task of the Ministry of Education on studying the core literacy of domestic students. On March 30, 2014, the MOE of the People's Republic of China officially promulgated "Opinions on Comprehensive Deepening Curriculum Reform, Implementing the Fundamental Task of Strengthen Moral-Education to Cultivate-People", which clearly put forward the new task of "developing core literacy system for students in each period" and "researching and formulating academic quality standards for various disciplines in primary and secondary schools", which points out the direction for deepening the curriculum reform of basic education with the goal of core quality. On September 13, 2016, Beijing Normal University held a launch event on the research results of Chinese students' core literacy, which clearly put forward three areas (Cultural Foundation, Independent Development and Social Participation), six kinds of literacy (Humanistic Connotations, Scientific Spirit, Learning to Learn, Healthy Life, Assuming Responsibility, Practical Innovation) and eighteen key points (Humanities Accumulation, Humanistic Feelings, Aesthetic Taste, Rational Thinking, Critical Questioning, Courage to Explore, be Willing to Learn and Good at Learning, Diligence in Reflection, Information Consciousness, Cherishing Life, Sound Personality, Self-management, Social Responsibility, National Identity, International Understanding, Labor Consciousness, Problem Solving, Technology Application) for the development of Chinese students' core literacy. Since then, student development core literacy has become the main content of reform and development of basic education in China, mainly include four aspects: Core literacy concept, content indicators, curriculum system, quality assurance index system. Next, this study will review and outlook the research results of Chinese students developing core literacy.

\section{Data Sources}

First, find the data. On September 30, 2017, the author entered the "Advanced Search" function of the CNKI (China National Knowledge Infrastructure) search database. Under the "Journal" status, the search title was "Core Literacy", the search condition was "Exact", and the search time was "2000-2017". The source categories are: "Core Journals" and "CSSCI (Chinese Social Sciences Citation Index)" (Note: "Core Journals" and "CSSCI" are the authoritative databases of 
scientific research and publication in China. The purpose of selecting these two databases is to increase the representation of quoted data. That is to say, the paper selected in this paper is the authoritative representative of China's scientific research results), and a total of 445 documents and various materials were retrieved. Second, determine the research data. In 445 pieces of literature data, through the artificial screening of "book reviews", "no keywords", "no author information", "conference summary", "report interpretation", "repeated literature", etc. and other non-research literature types data, and literature that are clearly unrelated to the subject of this search 69 articles in total, and a total of 376 valid literature were obtained. Finally, normative the data. Normalize the synonymous phenomenon in the keyword, for example, "cultivation path", "training way" and "cultivation strategy" should be unified as "cultivation path".

\section{Research Method}

\subsection{Research Tools}

Two softwares, Bibliographic Item Co-Occurrence Matrix Builder 2.01 (BICOMB 2.01) and Statistical Product and Service Solutions 20.0 (IBM SPSS Statistics 20.0), jointly developed by Professor Cui, L. of the Medical Information Department of China Medical University and Shenyang Hongsheng Computer Technology Co., Ltd. were selected.

\subsection{Research Process}

First, choose research data. The 376 valid literature retrieved are exported in "NoteFirst" format and saved as a ".txt" text file. The exported text files mainly include five topics: each literature title, abstract, keyword, and journal name. Second, establish new projects. BICOMB word frequency analysis software is used to create a new project, NO. 001, and the format type of the new project is "CNKI. Chinese. <TXT>". Third, extract keywords. The BICOMB word frequency analysis software was used to keywords extract, clean up and classify 376 valid literature. Fourth, matrix analysis. Using BICOMB Word frequency analysis software to generated the lexical matrix and co-present matrix of high frequency keywords. Fifth, cluster analysis. Lexical matrix and dissimilarity matrix were imported into SPSS 20.0 to form clustering tree diagram and hot spot knowledge map of high frequency keywords respectively. Finally, combined with the above analysis results, semantic analysis and content analysis are carried out to reveal the hot spots field and expansion trends of core literacy hot spot research in China.

\section{Data Processing and Result Analysis}

\subsection{Basic Profile of the Research Objects and Confirmation of High Frequency Keywords}

5.1.1. Age and Quantity of Publication and Its Analysis

It can be seen from Table 1 that China's core literacy research shows an increasing 
Table 1. The published day and number distribution of core literacy studies from 2000 to 2017.

\begin{tabular}{ccccc}
\hline Number & $\begin{array}{c}\text { Key Fields } \\
\text { (Year) }\end{array}$ & $\begin{array}{c}\text { Occurrence } \\
\text { Frequency (Times) }\end{array}$ & Percentage (\%) & $\begin{array}{c}\text { Accumulated } \\
\text { Percentage (\%) }\end{array}$ \\
\hline 1 & 2017 & 193 & 51.3298 & 51.3298 \\
2 & 2016 & 147 & 39.0957 & 90.4255 \\
3 & 2015 & 23 & 6.1170 & 96.5426 \\
4 & 2014 & 6 & 1.5957 & 98.1383 \\
5 & 2013 & 4 & 1.0638 & 99.2021 \\
6 & 2009 & 1 & .2660 & 99.4681 \\
7 & 2011 & 1 & .2660 & 99.7340 \\
8 & 2012 & 1 & .2660 & 100.0000 \\
\hline
\end{tabular}

trend year by year. Among them, the growth from 2000 to 2014 was very slow, it grew more rapidly in 2015, and it showed witnessed increase by leaps and bounds with a growth rate of $84.3 \%$ in 2016 . However, it should be pointed out that the statistical time of this study is September 2017, and some data are incomplete, but it is predicted that the number of documents in 2017 will still continue to rise trend.

\subsubsection{Published Author Unit Distribution and Analysis.}

Statistics show that 376 core literacy research papers come from 335 research institutions. In general, the distribution of authors unit for core literacy research is mainly concentrated in the education colleges, education departments, research institutes and research centers of well-known normal universities, while the proportion of other research institutions is significantly lower, such as Beijing Normal University China Basic Education Quality Monitoring Collaborative Innovation Center (15 times), East China Normal University Curriculum and Teaching Research Institute (13 times), Northeast Normal University Education Department (10 times). To some extent, it shows that the educational research institutions of well-known normal universities in China are engaged in the related research and exploration of China's core literacy, pay attention to the development of basic education, and have practiced the essential attribute of China normal university to contribute to the development of basic education. See Table 2.

\subsubsection{Journal Publication Amount and Analysis}

Statistics show that 376 core literacy research papers come from 66 journals, and journals with more than 16 number of articles published are mainly concentrated in the "Curriculum, Teaching Material and Method", "Primary and Secondary School Management", "Teaching \& Administration" and so on Chinese Core of Peking University and CSSCI Periodicals, this shows that core literacy research is closely related to curriculum, teaching and basic education. See Table 3. 
Table 2. Distribution of author units of core literacy research (partial).

\begin{tabular}{ccc}
\hline Number & Key Fields & $\begin{array}{c}\text { Occurrence } \\
\text { Frequency } \\
\text { (Times) }\end{array}$ \\
\hline 1 & Beijing Normal University China Basic Education & 15 \\
2 & Euality Monitoring Collaborative Innovation Center & 13 \\
3 & Northeast Normal University Department of Education & 10 \\
4 & Southwest University Faculty of Education & 8 \\
5 & Beijing Normal University Developmental Psychology Institute & 8 \\
\hline
\end{tabular}

Table 3. Journal publication amount of core literacy research (partial).

\begin{tabular}{ccc}
\hline Number & Key Fields & $\begin{array}{c}\text { Occurrence } \\
\text { Frequency } \\
\text { (Times) }\end{array}$ \\
\hline 1 & Curriculum, Teaching Material and Method & 43 \\
2 & Primary and Secondary School Management & 32 \\
3 & Journal of Teaching and Management & 26 \\
4 & The Inservice Education and Training of School Teachers & 24 \\
5 & Global Education & 22 \\
\hline
\end{tabular}

\subsubsection{Word Frequency Confirmation and Analysis of High Frequency Keywords}

Through statistical analysis of 376 valid documents, a total of 1736 keywords were obtained, and the keywords were standardized processing. According to the ZIPF high and low frequency keyword definition formula (Donohue, 1973: p. 49), as well as the Chinese scholar Sun, Q. L. proposed the high and low frequency keywords demarcation formula and word frequency estimation method (Sun, 1992), comprehensive considering the situation of this study, the frequency is 7 times (including) or more was determined as a high-frequency keyword, there are 29 high-frequency keywords in all (according to statistics and calculations, the frequency of occurrence of high-frequency keywords is 541 times, and the cumulative percentage is $31.2 \%$, which exceeds the $27 \%$ standard specified by the knowledge map analysis, and meets the analysis requirements). See Table 4.

The data in Table 4 shows that the frequency of high-frequency keywords in 29 core literacy studies is 541 times, accounting for 31.16 times of the total frequency of keyword occurrences. These words reflect the hot spots of core literacy research field in China to a large extent and trends. Among of them the word frequency of the top 12 keywords all is greater than 10, followed by core literacy (242 times), discipline core literacy (22 times), curriculum reform (21 times), cultivation path (15 times), and student core literacy (14 times), basic education field (14 times), practical inquiry (14 times), mathematical literacy (14 times), independent development (11 times), evaluation system (11 times), value orientation (11 times), classroom instruction (11 times). The frequency of the 
Table 4. Top 29 high frequency keyword rankings in core literacy research.

\begin{tabular}{|c|c|c|c|}
\hline Number & Key Fields & $\begin{array}{c}\text { Occurrence } \\
\text { Frequency (Times) }\end{array}$ & $\begin{array}{c}\text { Accumulated } \\
\text { percentage (\%) }\end{array}$ \\
\hline 1 & core literacy & 242 & 13.9401 \\
\hline 2 & discipline core literacy & 22 & 15.2074 \\
\hline 3 & curriculum reform & 21 & 16.4171 \\
\hline 4 & cultivation path & 15 & 17.2811 \\
\hline 5 & student core literacy & 14 & 18.0876 \\
\hline 6 & basic education field & 14 & 18.8940 \\
\hline 7 & practical inquiry & 14 & 19.7005 \\
\hline 8 & mathematical literacy & 14 & 20.5069 \\
\hline 9 & independent development & 11 & 21.1406 \\
\hline 10 & evaluation system & 11 & 21.7742 \\
\hline 11 & value orientation & 11 & 22.4078 \\
\hline 12 & classroom instruction & 11 & 23.0415 \\
\hline 13 & core literacy of student development & 10 & 23.6175 \\
\hline 14 & evaluation & 10 & 24.1935 \\
\hline 15 & students' development & 10 & 24.7696 \\
\hline 16 & innovation and entrepreneurship & 10 & 25.3456 \\
\hline 17 & strengthen moral education and cultivate people & 9 & 25.8641 \\
\hline 18 & school-based curriculum & 9 & 26.3825 \\
\hline 19 & teaching reform & 9 & 26.9009 \\
\hline 20 & Chinese students and core literacy & 8 & 27.3618 \\
\hline 21 & curriculum standards & 8 & 27.8226 \\
\hline 22 & three-dimensional target & 8 & 28.2834 \\
\hline 23 & all-round development of human being & 8 & 28.7442 \\
\hline 24 & curriculum system & 7 & 29.1475 \\
\hline 25 & quality education & 7 & 29.5507 \\
\hline 26 & talent training & 7 & 29.9539 \\
\hline 27 & curriculum design and development & 7 & 30.3571 \\
\hline 28 & Chinese & 7 & 30.7604 \\
\hline 29 & Chinese core literacy & 7 & 31.1636 \\
\hline Total & & 541 & \\
\hline
\end{tabular}

remaining 17 keywords all is greater than or equal to 7 . This result indicates that most of China's core literacy research around the subject research of core literacy and mathematics literacy, student core literacy and student independent development, curriculum reform and classroom teaching, cultivation path and practice inquiry, core literacy and basic education and other aspect theme re- 
search. However, this is only the aggregation and presentation of preliminary high-frequency keywords; it's also hard to find the interrelation between keywords, which requires further data mining and precision presentation.

\subsection{High Frequency Keyword Matrix Analysis}

Generate lexical matrix through BICOMB software. The lexical matrix is imported into SPSS 20.0 analysis software, and a $29 \times 29$ core literacy high frequency keyword similarity matrix is generated by OCHIAI coefficient. See Table 5 for details. In the similar matrix, the closer the value between the two keywords is to 1 , it shows that the closer the distance between the two keywords is, the larger the similarity is. On the contrary, the closer the value is to 0 , indicates that the further the distance between the two keywords is, the smaller the similarity is; then, using Excel tables, subtracting the similarity matrix with "1" to obtain the data table of the dissimilarity matrix, as shown in Table 6. In the dissimilarity matrix, the closer the value is to 0 , the closer the relationship between the two keywords is, and the closer the relationship is to the research topic. On the contrary, the closer the value is to 1 , the more distant the relationship between the two keywords is, the deviation from the research topic or irrelevant.

As can be seen from the data in Table 5, in the order of each keyword distance "core literacy" from near to far is the curriculum reform (0.238), the cultivation path (0.155), the basic education field (0.137), the practice inquiry (0.130), subject core literacy (0.126), evaluation system (0.121), mathematical literacy (0.069),

Table 5. Core literacy research high frequency keywords ochiai coefficient similarity matrix (partial).

\begin{tabular}{cccccc}
\hline & $\begin{array}{c}\text { core } \\
\text { literacy }\end{array}$ & $\begin{array}{c}\text { discipline } \\
\text { core literacy }\end{array}$ & $\begin{array}{c}\text { curriculum } \\
\text { reform }\end{array}$ & $\begin{array}{c}\text { cultivation } \\
\text { path }\end{array}$ & $\begin{array}{c}\text { student } \\
\text { core literacy }\end{array}$ \\
\hline core literacy & 1.000 & .126 & .238 & .155 & .000 \\
discipline core literacy & .126 & 1.000 & .000 & .117 & .000 \\
curriculum reform & .238 & .000 & 1.000 & .000 & .000 \\
cultivation path & .155 & .117 & .000 & 1.000 & .071 \\
student core literacy & .000 & .000 & .000 & .071 & 1.000
\end{tabular}

Table 6. Core literacy studies the dissimilarity matrix of high-frequency keywords (partial).

\begin{tabular}{cccccc}
\hline & $\begin{array}{c}\text { core } \\
\text { literacy }\end{array}$ & $\begin{array}{c}\text { discipline } \\
\text { core literacy }\end{array}$ & $\begin{array}{c}\text { curriculum } \\
\text { reform }\end{array}$ & $\begin{array}{c}\text { cultivation } \\
\text { path }\end{array}$ & $\begin{array}{c}\text { student } \\
\text { core literacy }\end{array}$ \\
\hline core literacy & .000 & .874 & .762 & .845 & 1.000 \\
discipline core literacy & .874 & .000 & 1.000 & .883 & 1.000 \\
curriculum reform & .762 & 1.000 & .000 & 1.000 & 1.000 \\
cultivation path & .845 & .883 & 1.000 & .000 & .929 \\
student core literacy & 1.000 & 1.000 & 1.000 & .929 & .000
\end{tabular}


independent development (0.039), and student core literacy (0.000). This result indicates that most scholars have combined "core literacy" with "curriculum reform", "cultivation path", "basic education field", "practical inquiry" and "discipline core literacy" this five keywords to discuss in research.

\subsection{High Frequency Keyword Clustering Tree Diagram and Analysis}

In order to more accurately reflect the intimacy between keywords, to further present the research hot spots and trends of core literacy, the researchers clustered analysis the high frequency keywords of this literature. The closer the keywords are, the distance of they are more closer; on the contrary, the distance of they are more farther (Guo \& Fang, 2015). The lexical matrix was imported into SPSS 20.0 for cluster analysis of core literacy high frequency keyword system. The results are shown in Figure 1.

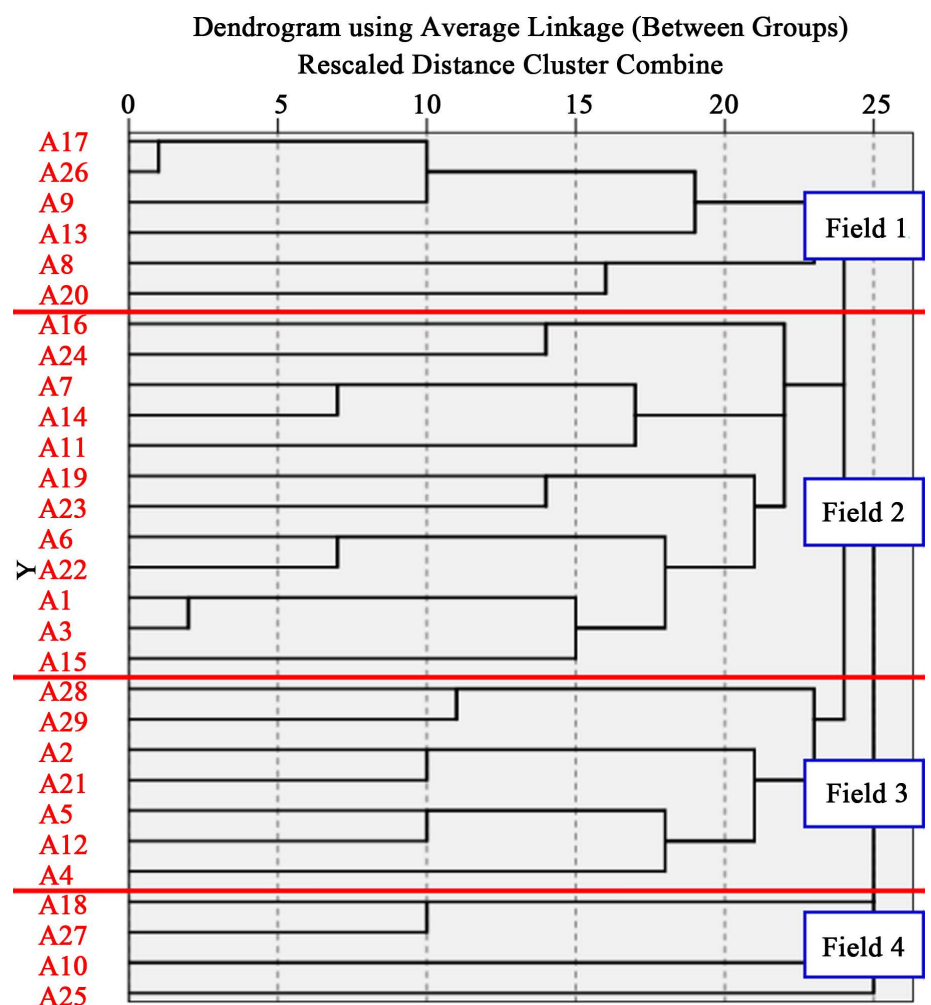

Figure 1. Core Literacy High Frequency Keyword Clustering Tree Figure. Field 1: A17. strengthen moral education and cultivate people. A26. talent training. A9. independent development. A13. core literacy of student development. A8. mathematical literacy. A20. Chinese students and core literacy. Field 2: A16. innovation and entrepreneurship. A24. curriculum system. A7. practical inquiry. A14. evaluation. A11. value orientation. A19. teaching reform. A23. all-round development of human being. A6. basic education field. A22. three-dimensional target. A1. core literacy. A3. curriculum reform. A15. students' development. Field 3: A28. Chinese. A29. Chinese core literacy. A2. discipline core literacy. A21. curriculum standards. A5. student core literacy. A12. classroom instruction. A4. cultivation path. Field 4: A18. school-based curriculum. A27. curriculum design and development. A10. evaluation system. A25. quality education. 
According to the Figure 1 high-frequency keywords' clustering results display clustering group connection distance far and near which can be concluded that the domestic core literacy research hot spots mainly focus on four major areas: Field 1 includes the words strengthen moral education and cultivate people, talent training, independent development, and core literacy of student development, etc. keywords. Field 2 includes key words such as innovation and entrepreneurship, curriculum system, and teaching reform, etc. keywords. Field 3 includes keywords such as Chinese, discipline core literacy, curriculum standards, and classroom instruction, etc. keywords. Field 4 includes keywords such as school-based curriculum, curriculum design and development, evaluation system, and quality education, etc. keywords.

\subsection{High Frequency Keywords Multidimensional Scale Analysis and Composition of Knowledge Mapping}

Multidimensional scale analysis can objectively and accurately reflect the degree of similarity (dissimilarity) among multiple research objects, so as to more appropriately find out the expression of the research data. The dissimilarity matrix was imported into SPSS 20.0 statistical software for multidimensional scale analysis, and the core literacy research field and hot knowledge map of China were drawn. The results are shown in Figure 2.

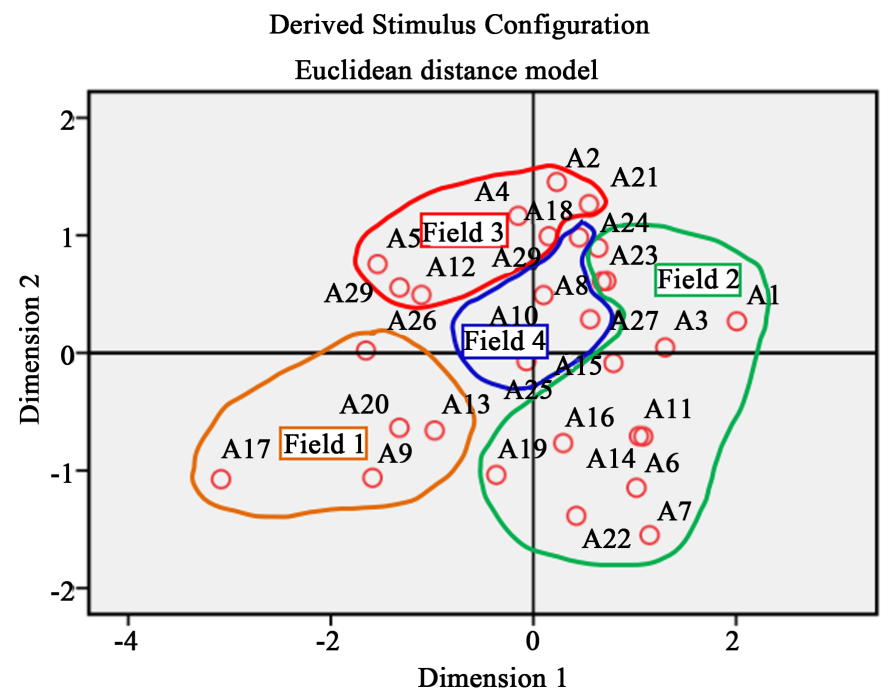

Figure 2. Core Literacy Research Hot Spot Knowledge Map. Field 1: A17. strengthen moral education and cultivate people. A26. talent training. A9. independent development. A13. core literacy of student development. A8. mathematical literacy. A20. Chinese students and core literacy. Field 2: A16. innovation and entrepreneurship. A24. curriculum system. A7. practical inquiry. A14. evaluation. A11. value orientation. A19. teaching reform. A23. all-round development of human being. A6. basic education field. A22. three-dimensional target. A1. core literacy. A3. curriculum reform. A15. students' development. Field 3: A28. Chinese. A29. Chinese core literacy. A2. discipline core literacy. A21. curriculum standards. A5. student core literacy. A12. classroom instruction. A4. cultivation path. Field 4: A18. school-based curriculum. A27. curriculum design and development. A10. evaluation system. A25. quality education. 
Combined with Figure 1 and Figure 2, the co-occurrence knowledge map of high-frequency keywords is roughly consistent with the clustering tree map. In this strategic coordinate graph, the position of each keyword is represented by a small circle. The closer the mutual relationship of the keywords, the closer the circles distance they represent to each other; otherwise, the opposite. The specific analysis is as follows: The keywords in the first quadrant are closely related to each other, and the distance from the center of the coordinate is relatively close, indicating that the research is at the center and the internal consistency is high, which is a hot research field at present. The keywords in the second quadrant are closely related and clear, indicating that some research institutions have conducted research on them. The keywords in the third quadrant are relatively loosely distributed and far from the center point, it shows that there are also descriptions potential development and research space. The keyword distribution of the fourth quadrant is relatively concentrated and of potential importance, and it is representatives of some research institutes have made further studies on it.

\subsection{Result Analysis}

\subsubsection{Strengthen Moral Education and Cultivate People and Student Develop Core Literacy and Its Talent Cultivation Research}

"Strengthen moral education and cultivate people" and student development core literacy and its talent cultivation research are mainly composed of keywords such as "strengthen moral education and cultivate people, talent cultivation and independent development". Chinese scholars pay attention to the core literacy mainly originate from the gradual development and evolution of the "Formulation of 2000 Rippens Strategy" and the "Education and Training 2010 Program (ET2010) and Lifelong Learning Program" in the European Union (EU) education reform movement after the 21 st century. The so-called "core literacy of student development" mainly refers to the students should have the necessary character and key ability to adapt to the needs of lifelong development and social development (Lin, 2017), it has commonality, development and can be teach-learn three characteristics (Xin, Jiang, Lin, Shi, \& Liu, 2016). So, what are the necessary links between "strengthen moral education and cultivate people" and "core literacy of student development"? Why is there such a wide focus? Throughout the historical changes in China's education reform, in 2013, the Chinese Communist Party's (CCP) “18th National Congress” proposed an education policy to "strengthen moral education and cultivate people" as the fundamental task of education. In 2014, the core literacy system of student development was proposed. In 2016, the ministry of education released the "China Student Development Core Literacy". Thus, the direction of education reform is clarified, and the essential function and true value of education are responded, that is, considering the fundamental problem of education from the national level, education should "set up what virtue, training what person" or "cultivate what kind of person". For example, from the essence of education, Lin, C. D. believes that attention to 
student development core literacy is to fully implement the party's educational policy. It is the answer to the fundamental question of pay attention to the "set up what virtue, training what person" and "what kind of person should be trained for the future" (Lin, 2016). Zhao, J. X. et al. proceeded from the framework of constructing student development core literacy, and believed that the core literacy framework of students is the key and foundation for implementing the fundamental task of "Strengthen Moral Education and Cultivate People". This is an inevitable requirement of inheriting the excellent traditional culture of the Chinese nation. At the same time, it is necessary to integrate the outstanding genes of Chinese culture into the student development core literacy (Zhao, Peng, \& Zhang, 2016). It can be seen that the "Strengthen Moral Education and Cultivate People" and the student development core literacy research are inextricably linked, which is the echo and extension of the national education reform level; in a sense, it also reflects the current core literacy research showing the characteristics of the times, rationality, scientificity and development. Of course, based on the student development core literacy education mode, different scholars will understand the relevance of the student development core literacy and the talent training research in the field from different perspectives. The performance is as follows: First, research on talent training in universities (including higher vocational colleges). Chen, H. Y. proposed to learn from the "Chinese student development core literacy" education mode, should reconstruct the current training mode of preschool education professionals in colleges and universities, which is reflected in the improvement of talent training objectives, the clarification of talent training specifications, the scientific construction of characteristic courses, the reconstruction of student evaluation systems, the guide of teachers' professional development, and the strengthening of campus culture construction and other aspects (Chen, 2017). The second is the research on the training of basic education talents. Huang, B. Q. believes that core literacy is the key direction of future curriculum reform. And from the three aspects of "curriculum reform based on student core literacy, insisting on curriculum educate people; changing teaching methods, insisting on educating people in classroom teaching and extracurricular activities; changing the traditional education quality evaluation view, insist on education quality evaluation to educate people", the current path of talent training in primary and secondary schools is proposed (Huang, 2016).

\subsubsection{Teaching Reform and Its Practical Research of Basic Education Course Based on Core Literacy}

Teaching reform and its practice research of basic education curriculum based on core literacy, it is the biggest hot spot of core literacy research in China; it is mainly composed of keywords such as "innovation and entrepreneurship, curriculum system and teaching reform". The curriculum is an important carrier for achieving educational goals. Curriculum reform is a booster for education reform, construction and development. At present, the reform of the curriculum system under the core literacy perspective is not only a new trend in the reform 
of the international curriculum field, but also an era appeal for the in-depth promotion of basic education curriculum reform and practice in China. It has become the consensus of the education community. And the landing (or development) of the core literacy of students is more directed to the systematic design and implementation of the curriculum. So, how to make the core literacy and the curriculum system reform closely connected? It mainly forms a horizon which based on core literacy (value orientation or pursuit of ideas), and believes that the curriculum system construction should be constructed from the top level design of the curriculum, curriculum standards, curriculum objectives, curriculum settings (course content and structure), curriculum implementation, curriculum evaluation, schooling system and multilateral coordination and other aspects highlight the core literacy connotation and essentials, thus systematically constructing different perspectives such as the curriculum system. Due to the limitation of length, several points will be briefly described. In terms of curriculum top level design and curriculum standards, Xie, J. T. and Wang, M. based on core literacy content framework and domestic and foreign experience, proposed path selection and implementation recommendations from curriculum top level design, curriculum standards development, multilateral coordination mechanism (Xie \& Wang, 2016). He, H. believes that the curriculum standards, course content, and course structure should be reconstructed to build a new curriculum system that meets the core literacy of Chinese students (He, 2017). Some scholars also discuss the construction of core literacy and curriculum system from the perspective of specific disciplines. For example, $\mathrm{Li}, \mathrm{X}$. Y. based on the thinking of math core literacy, put forward the proposal for the construction of the curriculum system of primary mathematics education, which is reflected in the formulation of a unified national training standard, the strengthening of links with primary school mathematics curriculum, and constructing a practical course with reflective and cooperative nature (Li, 2016). At the same time, some scholars also have introduced three models of core literacy and curriculum system reform current in the major foreign countries (American model, Japanese model, Finnish model), pointing out the challenges faced by curriculum standards based on core literacy, the relationship between curriculum system and content and various parts. In addition, with the deep transformation and development of China's economy and society, the "Educational Modernization", "Big Data", "Mass Entrepreneurship, Innovation”, "Internet+" strategy put forward, the requirements for all-round talents are getting higher and higher. The "Core Literacy" education concept is adapting to the demands of this strategy; entrepreneurial education based on core literacy has also attracted the research and focus of many scholars. Based on the international perspective of core literacy, $\mathrm{Chu}, \mathrm{H}$. Q. deeply analyzes the connotation, extension, essential requirements and deep background of core literacy, and proposes a educational orientation that innovation ability is the core of China's core literacy, and cultivating innovative talents is the priority goal of Chinese education (Chu, 2016). However, for 
the innovation consciousness, innovation accomplishment, innovation ability, innovation thinking, etc. innovative education and core literacy docking, it presents that the present situation of current situation of more research in universities, and less research on basic education (or specific subject); as we all know, the cultivation of innovation awareness, innovation literacy and so on is not a fast-product, which needs to go through the whole process of talent cultivation and development which remains to be thorough.

\subsubsection{Research on Discipline Core Literacy and Classroom Teaching and Its Cultivating Path}

The research on subject core literacy and classroom teaching and its cultivation path is mainly composed of keywords such as "Chinese, classroom teaching and subject core literacy" and so on. The emergence of "Subject Core Literacy" is accompanied by the word "Core Literacy", which mainly discusses the mutual relationship between core literacy and subject, so as to fully implement core literacy, and then help students form a certain quality or improve a certain ability. The so-called "Subject Core Literacy" refers to the understanding of the nature of subject education and the structural system of subject quality under the care of core literacy (Liang \& Wang, 2017), important concepts, key abilities and Essential character acquired by learning knowledge and skills, ideas and methods of a subject (Shao, Zhou, \& Cui, 2015). So how to make the core literacy and subject correspondence and connection? It mainly forms the viewpoints of different subject core literacy such as Chinese, mathematics, biology, information technology and music. Some scholars believe that the core literacy of the Chinese subject is a highly concise and concentrated expression of the Chinese subject value system, highlighting the fundamental nature and basic characteristics of the Chinese subject, reflecting the rich connotation and practical requirements of the Chinese subject. Some scholars start from the practical effect and propose the trigonometric model (two levels, six literacy) of the core literacy system of primary school mathematics. Xiao, A. Q. and Yan, P. H. believe that the core quality of senior high school biology is a necessary quality and key ability for students Gradually formed to pay attention to personal life-long development and social development through the study of senior high school biology curriculum (2017). In addition, based on the guidance of the subject core literacy concept, many scholars have studied the relationship between the internal structure and the external structure of subject core literacy; the relationship between subject core literacy and curriculum standard (subject curriculum standards), curriculum setting, teaching objectives, teaching model, teaching content, teaching activities, student learning, training mode; in particular, the relationship between subject core literacy and curriculum standards and teaching. For example, some scholars absorb the experience of international curriculum standards development, from the perspective of the relationship between core literacy and subject course, they believes that course standard should be designed from the idea of "core literacy—subject core literacy—content standard" 
(Shao et al., 2015: p. 14), thus providing a path selection for the convergence of core literacy and subject course standard.

\subsubsection{School-Based Curriculum and Its Development Research under the Perspective of Core Literacy}

The school-based curriculum and its development research from the perspective of core literacy are mainly composed of keywords such as "school-based curriculum, curriculum design and development, and evaluation system". Since the implementation of the three-level curriculum management system in China, the development of school-based curriculum has become an important booster for curriculum reform. At present, cultivating students' core literacy is a topic that has been widely concerned and focused by the education community. It is the vane of future basic education curriculum reform. Therefore, core literacy and school-based curriculum will have inevitable internal relevance and value implication. From the perspective of core literacy, school-based curriculum development has two-way (commonness and individuality), duality (adult and talent), comprehensive (internal-external combination, plural subject), practical guidance (participation, innovation in cooperation) and adaptability of the times (the basic appeal of a particular period) and so on (Du \& Wang, 2017), especially in the hot spots such as "Big Data", "Internet+", "Cloud Computing", "Cloud Course", "Cloud Classroom", the development of school-based curriculum should be given special attention. For example, Jing, $\mathrm{X}$. $\mathrm{X}$. believes that the comprehensive practice activity curriculum innovation under the core literacy perspective should propose interdisciplinary integration, interdisciplinary team teaching and research, multi-subject participation, and multi-evaluation from the perspective of interdisciplinary integration. In order to effectively docking the fundamental optimization of "teachers' teaching" and "students' learning", and ultimately improve the comprehensive quality of teachers and students (Jing, 2017); Liu, G. F. analyzes the development and implementation of school-based curriculum from the perspective of core literacy, may face ideological concepts, system construction, teacher quality, parents and other related main bodies, school facilities and resources, and the quality of school-based courses and other questions, but did not come up with specific solutions (Liu \& Feng, 2016). Some researchers also based on the upsurge the development of The Times to re-examine the development of school-based curriculum. For example, based on the concept of core literacy and from the perspective of "Internet+", Li, W. S. and other scholars proposed to redefine the goal orientation of high school school-based curriculum development and the reconstructing discipline development, individual growth and social needs of three levels of the high school school-based curriculum development goal system (Li \& Liu, 2017).

\section{Conclusion and Recommendations}

Based on the above each analysis results, the conclusions and suggestions for the research on core literacy are as follows. 


\subsection{Main Research Conclusion}

\subsubsection{From the Perspective of Research Subject}

At present, the publishing units of research on core literacy involve a wide range of publishing units, and the strength of research units is not balanced. That is mainly manifested in: First, a wide coverage, involving colleges and universities, research institutes, educational examination institutes, publishing houses, magazines, primary and secondary schools and other multiple levels research subjects and various types of institutions. It contributes core literacy connect between theoretical research and practice exploration in entire field of education, and at the same time, it is conducive to the formation of research results from different research backgrounds and perspectives. Second, the research strength is not balanced. The well-known normal university shows great research strength, becomes the main force of research, and has many research achievements, while other institutions (integrated institutions, local colleges) and research institutions have become the secondary main force of research and have few research results.

\subsubsection{From the Perspective of Research Content}

Keywords such as "core literacy", "discipline core literacy", "basic education field", "curriculum reform", "mathematical literacy", and "practical inquiry" are highly concerned research topics or research hot spots. In this study, it can be specifically explained as follows: In recent years, "What is the core literacy, what problems have been solved and how are they implemented?" "How to carry out curriculum reform? How to integrate curriculum setting?" "What courses are set up? What are the courses taught, how are they taught, how do students learn, and who teaches them to achieve their training goals?" and other issues all have been repeatedly discussed based on the educational orientation of the new concept of "core literacy". The discussion of these issues provides some reference value and guidance for our country to re-examine the nature and value of education and what kind of people education should really cultivate. At the same time, it has played an important role in deepening the reform in the field of education and realizing the all-round development of human beings.

\subsubsection{From the Perspective of Research Methods}

At present, researchers mostly use the international more mature core literacy theory and empirical research for reference, while the localization theory and empirical researches are few. Although these research results have played a positive role in the exploration of core literacy issues in China, but the theoretical exploration that really suits China's national conditions and the reality of education development and effectively promotes the process of core literacy is insufficient. And the theoretical exploration with the characteristics of China's localization is also relatively scarce. In addition to China's special national conditions and the imbalance of education development, how to construct and apply the core literacy theory to guide the practice of China's education development is 
worth the academia's in-depth thinking.

\subsubsection{From the Perspective of Research}

Most of the research is from the macro level of curriculum and teaching reform, core literacy clarification, measurement and construction system, but this is only part of the problem of the key implementation areas of core literacy. For example, the study of "strengthen moral education and cultivate people" and "core literacy" focuses on the interpretation of macro-policy, lacking meso-level research and micro-level research. Therefore, "strengthen moral education and cultivate people" is in the third quadrant and is not closely connected with other keywords. In addition, student understanding, teacher understanding, teacher accomplishment, social participation (social identity, community education, enterprise education), family integration, school environment, school management system, government and university and primary \& secondary school integration training mode (U-G-S) and other issues should be given important attention. For example, the regional difference analysis of current core literacy research is basically absent. As is known to all, China is a country with extremely unbalanced economic development, which determines the unbalanced development in the field of education. Statistics on the current domestic core literacy research literature, regional differences in research still need to be further explored. In fact, the implementation of core literacy requires theoretical guidance and macro-thinking, and it is also inseparable from the regional background in which core literacy is carried out. Regardless of the dynamic factors or the conditions for realization, the explanations for leaving the regional economy and the social development environment are insufficient, and it is difficult to comprehensively plan and fully implement the basic connotation of core literacy. For example, the cultivation of information awareness is worth exactly to excavate and explore. Therefore, in the future, researchers need to continue to explore the path of solving these problems from a multidisciplinary and cross-disciplinary perspective, and provide suggestions for comprehensively addressing the various difficulties faced in the promotion of core literacy.

\subsubsection{This Study Has Certain Limitations}

In terms of keywords, the author cannot guarantee that all keywords in domestic core literacy research papers since 2000 are standardized, and subjective factors are inevitable in the process of standardization of keywords. On the one hand, some low-frequency keywords may become high-frequency keywords in the near future or more due to the influence of the paper itself and the influence of the time lag, which needs further attention and mining in the follow-up study.

\subsection{Suggestions for Future Research}

\subsubsection{Rationally Examine "Core Literacy" and Strengthen the Localization Research of Core Literacy}

The concept of "core literacy" was not born in China, but imported from the West. As a new model of education, core literacy has become a hot word in the 
field of education in the past two years. At present, there are already three-dimensional goals, quality education, comprehensive development, comprehensive quality of students and other education ideas. Is it necessary to put forward "core literacy"? Is it just "following the fashion"? Is it just a "concept game"? Classroom teaching capacity is limited. Therefore, how to promote the overall development of students in an effective capacity, it is indeed necessary to highlight the cultivation of key literacy. From an international perspective, the core literacy is not a "concept game". It has the background and changes of the times. It is a challenge to cope with the economic, information and globalization of the 21st century, and reflects the appeals of social change for the new talent structure. Therefore, core literacy is not an all-encompassing literacy "big hot pot", but has its specific directivity. It is the "concise" and "transcendence" of the entire literacy list, and it is the "key minority" literacy in three-dimensional goals and quality education, etc. In this sense, it is necessary to introduce, promote and reform core literacy. At present, the research on core literacy in China is still in the embryonic stage, and its research results are mainly in the stages of theoretical discussion, speculative deduction, curriculum system, evaluation system and teaching mode construction. For example, the research and introduction of the curriculum system construction in major countries such as the United States, Finland, Japan, South Korea, Singapore, Australia, and Spain. In the research of Chinese indigenous, only Lin, C. D. scholars of Beijing Normal University put forward the core literacy index system of Chinese students and the " $1+X$ curriculum" practice case of the affiliated primary school of Tsinghua University on the basis of sufficient empirical research. Therefore, it is imperative to localize the core literacy research, especially the empirical research.

\subsubsection{Straighten out the Relationship between "Core Literacy" and "Discipline Core Literacy"}

Subject core literacy is the second key word in this research, which indicates that it is inevitably related to core literacy. The proposal of discipline core accomplishment is discussed with the appearance of core accomplishment and is the link between solving core accomplishment and educational practice. Core literacy points to people, and discipline core literacy points to disciplines; core literacy emphasizes fundamentality, intercommunity, and interdisciplinary, and discipline core literacy emphasizes disciplinarity, academic nature, and professionalism. In fact, the current core literacy research should not explore what its content is? What is the core? If researchers delve into this, they will inevitably move toward "multi-core" and the situation of divestiture of core literacy. Researchers should focus on "what kind of person does education cultivate" and highly concise the fundamental nature, basic characteristics, and value core of the discipline, and focus on cultivating core literate people to seek integration with other disciplines. There should be such a system of core literacy indicators so that each discipline can construct its own discipline system under the overall index system of core literacy, because no discipline can contain all the contents 
of core literacy. Therefore, it is necessary to integrate the synergies of various disciplines, and to deal with the relationship between the whole and the local, commonality and individuality, etc. so that can achieve core literacy and truly return to the essential function and true value of education.

\subsubsection{Reconstruct the Paradigm of Teacher Education and Teacher Professional Development}

In this study, keywords such as "teacher education", "normal education" and "teacher professional development" did not appear in the first 29 high-frequency words, while the word frequency of occurrence of keywords such as "teacher core literacy" and "class teacher core literacy" was 4 . This result shows that teacher literacy has not attracted widespread attention. Teachers are important practitioners of deepening education reform in China and the first person to cultivate students to develop comprehensively in school education. At present, the country takes the cultivation of students' core literacy as the important guidance of deepening education reform in China. From this perspective, teachers also become the first cultivator to cultivate students' core literacy. Therefore, while discussing how to cultivate students' core literacy, we should also reform the current mode of teacher education development. Based on the framework of students' core literacy, condenses has the Chinese characteristic teacher's core literacy standard, so as to cultivate teachers suitable for the new round of basic education reform and great reform era. At the same time, the top-level design of pre-job and post-job integration of teachers should be done well. Teacher training and teaching activities should be taken as the starting point, and relevant contents and policies of students' core literacy should be integrated, so as to promote the sublimation of teacher professional development capacity while cultivating students' core literacy.

\section{Acknowledgements}

This research was supported by Research Achievements of the Graduate Innovation Fund Project of Gannan Normal University in Jiangxi Province, China (2018) "Empirical Study on the Influence of Teachers' autonomous support and Family Education on Children's Learning Quality" (Project No. YCX18A010), China Jiangxi Province Graduate Innovation Special Funding Project (2018) "Interactive Research in Cloud Classroom from an Ecological Perspective-Based on Empirical Research of Three Primary and Secondary Schools" (Project No. YC2018-S388), Jiangxi University Humanities and Social Sciences Research Project (2018) "Study on the Present Situation of Preschool Teacher Education Development and Quality Assurance Mechanism" (Project No. JY18119), China's Jiangxi Province Education Science Planning Project "Research on the Status and Cultivation of Left-behind Children's Learning Quality" (Project No. 17YB169), Humanities and Social Sciences Research Project of the Ministry of Education (2018) "Study on the Professional Development Model of Rural Teachers Based on the Overall Development of the School" (Project No. 


\section{YJA880014).}

\section{Conflicts of Interest}

The authors declare no conflicts of interest regarding the publication of this paper.

\section{References}

Chen, H. Y. (2017). Based on the "Core Literacy" to Optimize the Education Mode-A New Theory on Talent Cultivation in Colleges and Universities. Continuing Education Research, 9, 71-72.

Chu, H. Q. (2016). The International Vision of Core Literacy and China's Position-The Improvement of National Quality and the Transformation of Educational Goals in China in the 21st Century. Educational Research, 37, 8-18.

Docin (2015). Building Knowledge-Based Core Competencies in the Flowing World. http://www.docin.com/p-1147653922.html

Donohue, J. C. (1973). Understanding Scientific Literatures: A Bibliometric Approach. Cambridge, MA: The MIT Press.

Du, S. R., \& Wang, X. D. (2017). The Development of School-Based Curriculum Based on the Core Literacy of Student Development: Connotation, Characteristics and Principles. The In-Service Education and Training of School Teachers, 8, 42-45.

European Council (2000). Lisbon European Council 23 and 24 March 2000 Presidency Conclusions. http://www.europarl.europa.eu/summits/lis1_en.htm

European Union (2006). Recommendation of the European Parliament and of the Council of 18 December 2006 on Key Competences for Lifelong Learning. Official Journal of the European Union, L394, 10-18.

Guo, W. B., \& Fang, J. M. (2015). Keyword Co-Word Analysis: A New Method of Higher Education Research. Higher Education Exploration, 9, 18.

He, H. (2017). Reconstruction of China's Basic Education Curriculum System under the Perspective of Core Literacy. Journal of Teaching and Management, 18, 8.

Huang, B. Q. (2016). Analysis on the Cultivation Path of Core Literacy of Primary and Middle School Students. Education Exploration, 11, 14-16.

Jing, X. X. (2017). Trans-Boundary Fusion: The Innovation of Comprehensive Practical Activities Curriculum under the Perspective of Core Literacy. Primary and Secondary School Management, 1, 52-53.

Li, W. S., \& Liu, J. L. (2017). Internet Age Reconstruction of the Development Goal System of High School-Based Curriculum Based on the Development of Students' Core Literacy. Theory and Practice of Education, 37, 7.

Li, X. Y. (2016). The Construction of Elementary Mathematics Teacher Curriculum System Based on Mathematical Core Literacy. Theory and Practice of Education, 36, 47-48.

Liang, L. W., \& Wang, X, M. (2017). The Connotation and Training Mode of Discipline Core Literacy. Primary \& Secondary Schooling Abroad, 2, 63-64.

Lin, C. D. (2016). Students Develop Core Literacy: What Kind of People Should Be Trained for the Future? Journal of the Chinese Society of Education, 6, 1.

Lin, C. D. (2017). Constructing Chinese Student Development Core Literacy. Journal of Beijing Normal University (Social Science Edition), 1, 66. 
Liu, G. F., \& Feng, H. (2016). Some Reflections about School-Based Curriculum under the Perspective of Core Literacy. Journal of Teaching and Management, 21, 76.

Shao, C. Y., Zhou, W. Y., \& Cui, Y. H. (2015). The Development of Curriculum Standards Based on Core Literacy: International Experience and Enlightenment. Global Education, 44, 14-17.

Sun, Q. L. (1992). The Boundary of High Frequency and Low Frequency Words and the Method of Word Frequency Estimation. Information Science, 2, 28.

Xiao, A. Q., \& Yan, P. H. (2017). The Connotation and Training Strategy of High School Bio-Core Literacy. The In-Service Education and Training of School Teachers, 6, 60.

Xie, J. T., \& Wang, M. (2016). The Construction of Curriculum System Based on Core Literacy. Contemporary Education and Culture, 8, 28-29.

Xin, T., Jiang, Y., Lin, C. D., Shi, B. G., \& Liu, X. (2016). On the Connotation Characteristics and Frame Positioning of Students to Develop Core Literacy. Journal of the Chinese Society of Education, 6, 5-6.

Zhao, J. X., Peng, Y. G., \& Zhang, W. X. (2016). Inheritance of Chinese Excellent Traditional Culture and Student Development Core Literacy Research. Journal of the Chinese Society of Education, 6, 23. 